\title{
Giant Radiation-Induced Thoracic Malignant Schwannoma
}

\author{
Mazen Sanoufa ${ }^{a}$, Mohammad Sami Walide,
}

\begin{abstract}
Schwannomas growing to large sizes in the thoracic cavity are rare. We report such a case in a patient with a history of Hodgkin's lymphoma and radiotherapy more than two decades before, an example of a radiation-induced malignant schwannoma with a bad prognosis.
\end{abstract}

Keywords: Giant Malignant Schwannoma; Hodgkin's Lymphoma; Radiotherapy

\section{Introduction}

Spinal schwannomas have an incidence of $0.3-0.4$ cases/100,000 persons per year and account for $25 \%$ of intradural spinal cord tumors $[1,2]$.

\section{Case Report}

A 42-year-old female presented to our emergency department with weakness and loss of sensation in the right foot of one week duration. General medical exam was unremarkable. Muscle strength in the right lower extremity was $1+$ and left lower extremity $3+$. Deep tendon reflexes were intact bilaterally. Toes were down-going bilaterally. She had stocking-like anesthesia in the entire right lower extremity

Manuscript accepted for publication September 15, 2010

${ }^{a}$ Medical Center of Central Georgia, 840 Pine Street, Suite 950, Macon, Georgia, USA

bCorresponding author: mswalid@yahoo.com

doi: $10.4021 / \mathrm{jmc} 55 \mathrm{w}$ and below the calf in the left lower extremity. She had a history of Hodgkin's lymphoma treated 22 years ago with radiation therapy. Magnetic resonance imaging (MRI) showed a huge $9.3 \times 9.4 \times 9.3 \mathrm{~cm}$ mass in the right thoracic cavity originating from the spinal canal (Fig. 1, 2). Fine needle aspiration revealed malignant schwannoma compatible with malignant peripheral nerve sheath tumor. The patient had T1-3 laminectomy and resection of the intradural-extramedullary neoplasm. She also had thoracotomy and resection of the intracavitary lesion. Unfortunately, the patient expired within several months after surgery.

\section{Discussion}

This is a very rare case of a giant type IV schwannoma growing in the confined space of the thoracic cavity without significant pulmonary symptoms. A giant type IV schwannoma is an intraspinal-extraspinal dumbbell-like tumor with the extraspinal component more than $2.5 \mathrm{~cm}$ in diameter [2]. Spinal schwannomas are mostly benign and extramedullary and rarely grow beyond $6-8 \mathrm{~cm}$ in diameter without giving significant symptoms [2-6]. They may, however, manifest themselves in different ways. For example, Georghiou et al., 2003, reported a 57-year-old woman who presented with progressively aggravated dyspnea at rest, productive cough, and a referred vague left chest pain. She was found to have a $12 \times 14 \mathrm{~cm}$ schwannoma compressing the upper lobe of the left lung and displacing the mediastinum with subocclusion of the main pulmonary artery [7]. Kara et al, 2002, reported a 45-year-old woman who presented with cough and mild sputum production and was found to have a $16 \mathrm{~cm}$ ancient schwannoma in her left hemithorax [8]. On the other hand, Kumar et al, 2006, reported an incidental finding of a $14 \times 15 \times 19 \mathrm{~cm}$ schwannoma in the right hemithorax of a 59-year-old woman [4]. Schwannomas, thus, can be insidious tumors that give subtle symptoms for many years before the patient decides to seek medical help [9] or discovering them by chance [10].

Our case is interesting because previous radiotherapy probably contributed to the pathogenesis of the schwannoma. These tumors can occur 10 to 50 years after the original 

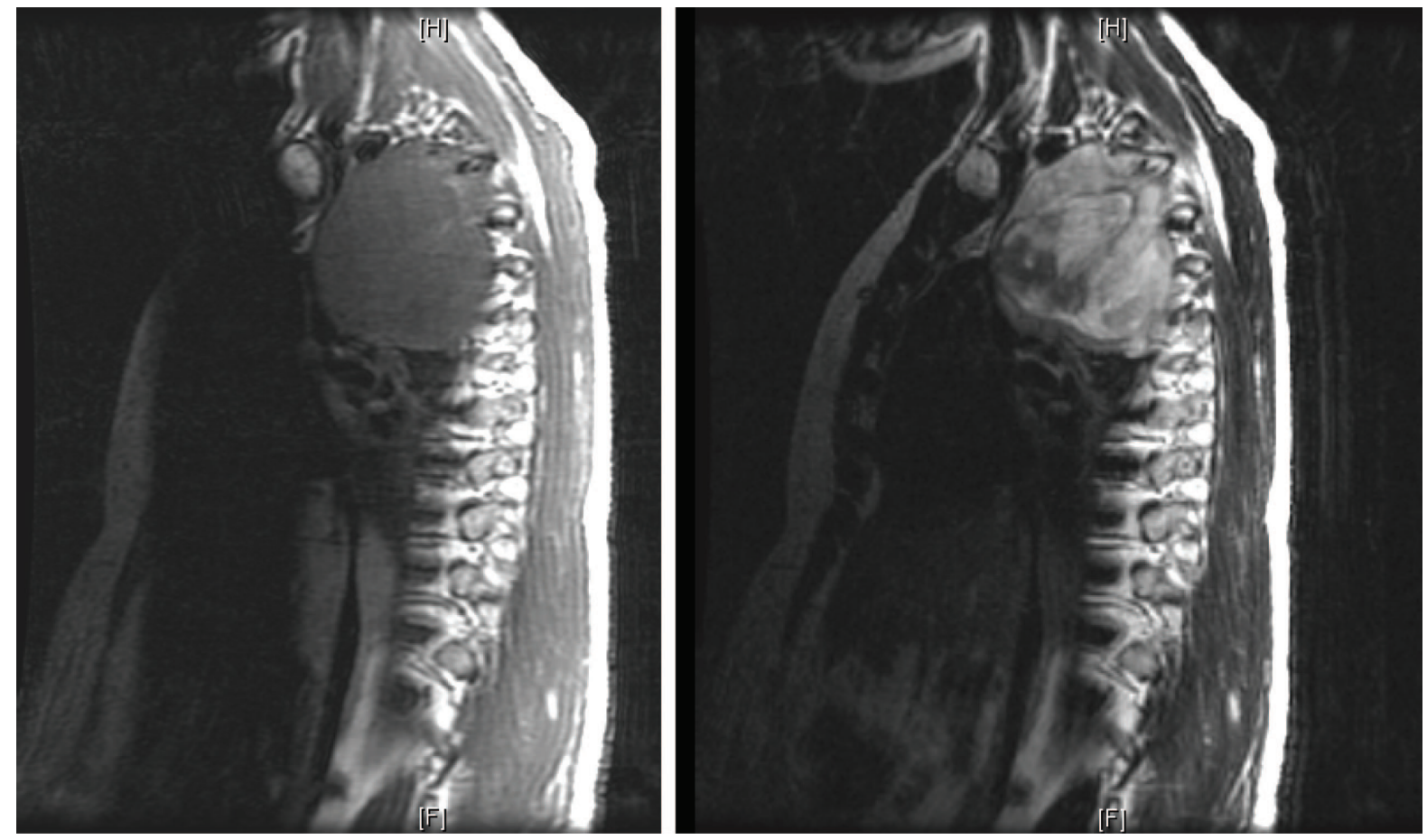

Figure 1. MRI T1 (left) and T2 (right) sagittal views of the thoracic cage.

radiation [11-14]. Malignant forms of these tumors have dim prognosis [15-17].

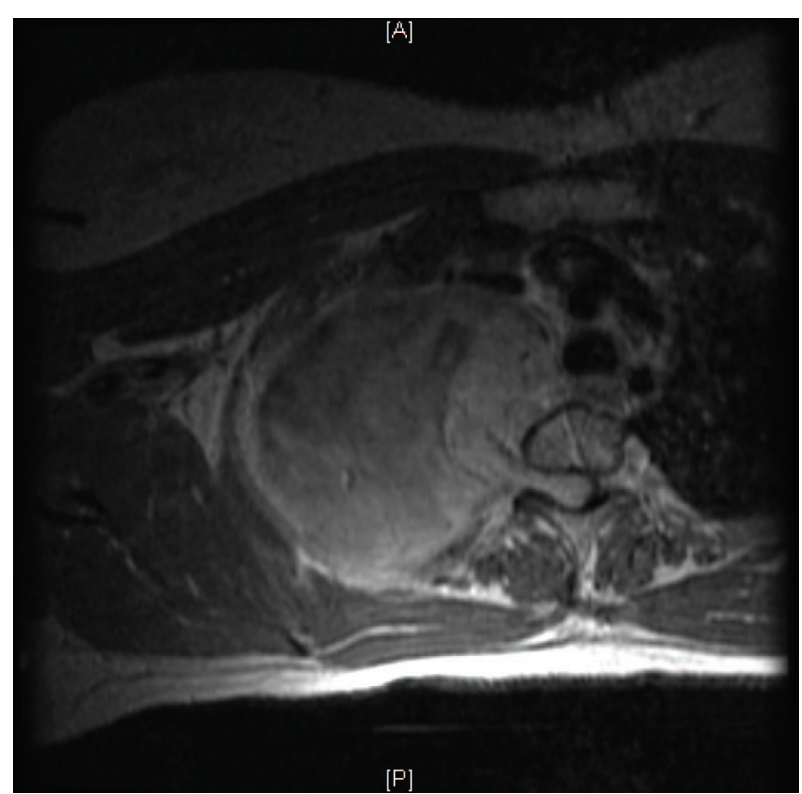

Figure 2. MRI T1 transverse view of the thoracic cage.

\section{References}

1. Sridhar K, Ramamurthi R, Vasudevan MC, Ramamurthi B. Giant invasive spinal schwannomas: definition and surgical management. J Neurosurg 2001;94(2 Suppl):210-215.

2. Jeon JH, Hwang HS, Jeong JH, Park SH, Moon JG, Kim $\mathrm{CH}$. Spinal schwannoma; analysis of 40 cases. J Korean Neurosurg Soc 2008;43(3):135-138.

3. Kyoshima K, Horiuchi T, Zenisaka H, Nakazato F. Thoracic dumbbell intra- and extramedullary schwannoma. J Clin Neurosci 2005;12(4):481-484.

4. Kumar S, Rafiq MU, Ahamed I, Ansari J, Cowen ME. Asymptomatic giant thoracic schwannoma. Ann Thorac Surg 2006;82(3):e26.

5. Hagiwara K, Higa T, Miyazato H, Nonaka S. A case of a giant schwannoma on the extremities. J Dermatol 1993;20(11):700-702.

6. Stout AP. The peripheral manifestation of the specific nerve sheath tumor (neurilemmoma). Amer J Cancer 1935; 24: 751-96.

7. Georghiou GP, Vidne BA, Boikov O, Saute M. Giant schwannoma of the posterior mediastinum. Eur J Cardiothorac Surg 2003;24(6):1030.

8. Kara M, Ozkan M, Sak SD, Aksu O, Kavukcu S. Giant ancient schwannoma of the posterior mediastinum cy- 
tologically misdiagnosed as a malignant tumour. A case report. Acta Chir Belg 2002;102(6):464-466.

9. Naganska E, Matyja E, Mossakowski Z, Zabek M. Giant cervico-thoracic schwannoma with long clinical history. Case report. Folia Neuropathol 1999;37(3):185-188.

10. Lucas S, Cendan E, Auque J, Civit T, Caremelle S, Braun D. [Asymptomatic giant thoracic dumbbell neurinoma. Apropos of a case]. J Chir (Paris) 1992;129(2):81-87.

11. Zadeh G, Buckle C, Shannon P, Massicotte EM, Wong S, Guha A. Radiation induced peripheral nerve tumors: case series and review of the literature. J Neurooncol 2007;83(2):205-212.

12. Morbidini-Gaffney S, Alpert TE, Hatoum GF, Sagerman RH. Benign pleural schwannoma secondary to radiotherapy for Hodgkin disease. Am J Clin Oncol 2005;28(6):640-641.

13. Kochbati L, Boussen H, Benna F, Belhaj Ali Z, Gammoudi A, Bouaouina N, Besbes M, et al. [Second ma- lignancies following Hodgkin's disease treatment in Tunisia. Retrospective study of 26 cases observed at the institute Salah-Azaiz]. Cancer Radiother 2003;7(5):302307.

14. Grudeva-Popova J, Goranov S, Kumchev I. Third malignancy after treatment of Hodgkin's disease. Folia Med (Plovdiv) 1999;41(2):13-15.

15. Fenzi F, Moretto G, Zamboni G, Passarin MG, Rizzuto N. Brain metastases from post-radiation malignant peripheral nerve sheath tumour. Ital J Neurol Sci 1995;16(7):495-498.

16. Watine O, Morel P, Bauters F, Ribet M. [Thoracic tumors after treatment for Hodgkin disease]. Ann Chir 1995;49(3):225-231.

17. Fisher PM, Dodwell DJ, Bridges LR, Cartwright SC, Stone J. Malignant schwannoma following treatment for Hodgkin's disease. Clin Oncol (R Coll Radiol) 1994;6(3):204-205. 